\title{
KONSEP PENDIDIKAN KARAKTER INDIGENOUS DALAM PERSPEKTIF ALQURAN
}

\author{
Yudianto Achmad \\ Ilmu Alquran dan Tafsir, Institut PTIQ Jakarta \\ yudiachmad@yahoo.com
}

\begin{abstract}
Abstrak: Pendidikan karakter dalam perspektif Islam dipandang sangat penting dan merupakan bagian tak terpisahkan dari konsep pendidikan Islam secara keseluruhan berdasarkan petunjuk Alquran. Penelitian ini bertujuan untuk mengungkapkan perumusan konsep dan model implementasi pendidikan karakter indigenous dalam perspektif Alquran untuk peserta didik di masa usia pranikah, prenatal, dan golden age. Penelitian ini menggunakan pendekatan kualitatif. Data dikumpulkan dengan melakukan observasi terhadap surat dan ayat-ayat Alquran, serta sains yang terkait dengan pendidikan karakter indigenous dalam perspektif Alquran, teknik analisis data menggunakan model analisis tafsir al-maudlu'iy. Hasil penelitian ini antara lain mengungkapkan tentang perumusan konsep dan model implementasi pendidikan karakter indigenous dalam perspektif Alquran di masa usia pranikah, prenatal, serta golden age. Simpulan dari penelitian ini antara lain bahwa dalam perspektif sains dan Alquran, manusia dari sejak dilahirkan memiliki dua jenis karakter indigenous yang berpasangan dan bersifat saling berlawanan, yakni karakter kebaikan (taqwa) dan karakter keburukan (fujur). Aktualisasi dan pengembangan karakter indigenous manusia dilakukan melalui pendidikan karakter yang memaksimalkan karakter kebaikan (taqwa) dan meminimalkan karakter keburukan (fujur).
\end{abstract}

Kata Kunci: Pendidikan karakter indigenous, taqwa, fujur, perspektif Alquran.

\section{CONCEPT OF INDIGENOUS CHARACTER EDUCATION IN THE QUR'AN PERSPECTIVE}

Abstract: Character education in Islamic perspective is considered very important
and is an inseparable part of the concept of Islamic education as a whole based on
Qur'anic instructions. This study aims to reveal the formulation of concepts and
models for the implementation of indigenous character education in the
perspective of the Qur'an for students in premarital, prenatal, and golden age. This
research uses a qualitative approach. Data is collected by observing the letters and
verses of the Qur'an, as well as science related to indigenous character education
in the perspective of the Qur'an. The data analysis technique uses the analysis
model of al-maudlu'iy interpretation. The results of this study, among others,
reveal about the formulation of concepts and models for the implementation of 
indigenous character education in the perspective of the Qur'an at the time of premarital, prenatal, and golden age. The conclusions of this study include that in the perspective of science and the Qur'an, humans from birth have two types of indigenous characters that are paired and are antagonistic, namely the character of goodness (taqwa) and the character of badness (fujur). Actualization and development of indigenous character of human being is done through character education that maximizes the character of goodness (taqwa) and minimizes the character of badness (fujur).

Keywords: Indigenous character education, taqwa, fujur, Qur'an perspective.

\section{PENDAHULUAN}

Maraknya berbagai peristiwa dekadensi karakter di Indonesia hingga saat ini, mengakibatkan bermunculan kondisi "darurat" yang sangat meresahkan masyarakat, karena terjadi di setiap lapisan dalam aspek-aspek kehidupan masyarakat. Sedangkan berbagai kondisi "darurat" yang dimaksud itu antara lain seperti; "Darurat" Korupsi (Wapres RI, 2014); "Darurat" Narkoba (Liputan 6, 2015); "Darurat" Perilaku, Pelecehan dan Kekerasan Seksual (Komnas Perempuan, 2016); "Darurat" LGBT (Lesbian Gay Biseksual, Transgender) (Taufiq, 2018); "Darurat" Kriminalitas (BPS, 2017: 20); serta kondisi "darurat" lainnya yang disebabkan oleh terjadinya berbagai peristiwa dekadensi karakter. Dari berbagai peristiwa dekadensi karakter yang menimbulkan banyak kondisi "darurat" tersebut, di antaranya dilakukan oleh mereka yang termasuk dalam kategori usia anak dan remaja (usia "generasi penerus bangsa," (UU No. 35 Th. 2014), apabila hal tersebut disandingkan dengan indikator dari Lickona (1991) akan terlihat bahwa di Indonesia diduga telah terjadi kegagalan dalam pendidikan karakter, sehingga berbagai peristiwa dekadensi karakter tersebut dapat menjadi salah satu penyebab munculnya isu adanya kegagalan pendidikan karakter di Indonesia.

Selain itu sistem dan pelaksanaan pendidikan di Indonesia antara tahun 2001 hingga tahun 2017 dinilai buruk oleh berbagai lembagalembaga Internasional berdasarkan hasil riset yang dilakukan oleh mereka. Penilaian buruk dimaksud antara lain berasal dari lembagalembaga seperti dari: Political and Economic Risk Consultancy (PERC) yang menempatkan Indonesia pada urutan ke-12 dari 12 negara di Asia (Krisnawan, 2010); United Nations Educational Scientific and Cultural Organization (UNESCO) (UNESCO, 2011; 264); The Economist Intelligence Unit (EIU) (The EIU, 2012: 40, 2014: 20-21). 
Secara umum semua hasil penilaian antara tahun 2001 hingga tahun 2017 dari lembaga-lembaga dimaksud menyatakan bahwa Indonesia memiliki kondisi buruk di bawah standar ukuran yang ditetapkan oleh masing-masing lembaga-lembaga tersebut dalam pelaksanaan sistem pendidikan. Hal tersebut menyebabkan semakin memperkuat bergulirnya isu tentang adanya kegagalan pendidikan karakter di tengah-tengah masyarakat Indonesia.

Dikeluarkannya kebijakan berupa Undang-Undang Nomor 20 Tahun 2003 tentang Sistem Pendidikan Nasional, terlihat sebagai upaya pemerintah Indonesia mengatasi hal yang terkait dengan penilaian-penilaian dimaksud. Upaya pemerintah Indonesia berlanjut dengan menetapkan berbagai kebijakan yang terkait dengan sistem pendidikan termasuk pendidikan karakter, di antaranya dengan mengeluarkan kebijakan untuk menguatkan pendidikan karakter di Indonesia melalui Peraturan Presiden Nomor 87 Tahun 2017 tentang Penguatan Pendidikan Karakter. Kebijakan pemerintah Indonesia tersebut menunjukkan bahwa pelaksanaan sistem pendidikan yang menyeluruh di Indonesia, termasuk di dalamnya melibatkan mengenai pendidikan karakter, memegang peranan yang sangat penting dalam rangka membentuk, membangun karakter suatu bangsa, dan memiliki keterkaitan yang sangat erat dalam rangka pelaksanaan secara utuh dan menyeluruh dalam upaya proses nation character building (Samani \& Hariyanto, 2012: 1-2).

Pendidikan karakter atau dikenal dengan pendidikan akhlak dalam perspektif Islam, juga dipandang sangat penting dan merupakan bagian tak terpisahkan dari konsep pendidikan dalam Islam secara keseluruhan di dalam menjalani kehidupan dunia dengan berdasarkan petunjuk dari firmanfirman Allah Swt. dalam Alquran, serta ajaran dari Nabi Muhammad saw. sebagai Rasul-Nya. Selain itu, dalam perspektif Islam, berkaitan dengan pentingnya karakter manusia dan proses aktualisasi serta pengembangan karakter melalui pendidikan karakter, dijelaskan dalam Alquran bahwa manusia lahir ke dunia sedikit pun tidak memiliki pengetahuan, tetapi diberikan potensi indera, akal, serta hati oleh Allah Swt. (Q.S. al-Nahl [16]: 78).

Kondisi dimaksud dijelaskan dalam tafsir tematik bahwa potensipotensi fitrah manusia pemberian Allah Swt. yang dibawa dari sejak lahir tersebut, dapat teraktualisasikan ketika manusia memanfaatkan modalitasnya secara maksimal dalam berinteraksi dengan lingkungan alam dan sosial sebagai salah satu wujud rasa bersyukur kepada Allah Swt. (LPMA, 2010: 3).

Potensi-potensi alamiah manusia pemberian dari Allah Swt. dimaksud, Alquran menjelaskan 
antara lain seperti jasmani atau raga tubuh manusia (Q.S. al-Mu'minûn [23]: 2-14), serta potensi alamiah yang lainnya, termasuk jiwa atau nafs (Q.S. al-Syams [91]: 7) manusia yang ditengarai sebagai pembentuk karakter manusia. Hal tersebut seperti yang diuraikan Ibnu Sina, alFarabi, al-Kindi sebagaimana dikutip Syah Reza yang menjelaskan bahwa nafs/jiwa adalah merupakan elemen utama dari pembentuk karakter manusia (Reza, 2014: 266). Dari penjelasan dimaksud, terungkap bahwa karakter manusia adalah termasuk di antara potensi alamiah manusia pemberian Allah Swt. dari sejak dilahirkan, serta potensi alamiah ini dapat mengalami perubahan karena adanya suatu pengaruh.

Sementara itu dalam sains di bidang psychology, di antaranya pada subbidang indigenous psychology, yang merupakan pengembangan dari cabang ilmu psikologi, menyiratkan jika manusia memiliki karakter indigenous atau karakter dasar, asli, alamiah yang terbagi menjadi dua bagian dan bersifat ganda atau berpasangan, serta saling berlawanan, yakni: 1) karakter indigenous kebaikan; 2) karakter indigenous keburukan. Kedua karakter indigenous tersebut dapat terpengaruh oleh kondisi keindigenous-an manusia dalam konteks: keluarga, budaya asal, sosial, ekologis, historis, filosofis, dan lainnya yang terkait dengan karakter manusia. Sedangkan konsekuensi atas pemilihan kedua jenis karakter alamiah dari sejak dilahirkan atau karakter indigenous dimaksud, memiliki "reward" dan "punishment" yang didasarkan pada nilai etika, moral, dan aturan yang berlaku sesuai tempat, situasi, dan kondisi (Kim, Yang, \& Hwang, 2006).

Terkait dengan hal tersebut, Alquran di antaranya mengungkapkan bahwa manusia diberikan potensi alamiah bawaan sejak lahir dari Allah Swt., yakni suatu potensi karakter alamiah manusia -potensi alamiah nafs sebagai elemen pembentuk karakter manusia- yang berupa dua jenis karakter yang bersifat ganda/berpasangan dan saling berlawanan satu sama lain, yakni manusia tidak hanya diberikan potensi karakter alamiah yang bersifat kebaikan atau bersifat taqwa saja, tetapi manusia juga diberikan potensi karakter alamiah yang bersifat keburukan atau bersifat fujur (Q.S. Yusuf [12]: 53, Q.S. al-Syams [91]: 5-8).

Berdasarkan paparan beberapa fenomena di atas di dalam melakukan pendidikan karakter, pendidik atau orang tua perlu memahami karakter indigenous manusia, yakni memperhatikan sisi kebaikannya (taqwa) dengan upaya mengembangkan secara optimal dan upaya meminimalkan atau bahkan mengeliminasi serta menghilangkan 
sisi keburukannya (fujur). Semua uraian tersebut, menjadi dasar kuat dan layak bagi penulis untuk melakukan penelitian tentang penyusunan konsep dan model implementasi pendidikan karakter di masa pranikah, prenatal, serta golden age yang memperhatikan kondisi keindigenous-an karakter manusia dalam perspektif Alquran yang berjudul Konsep Pendidikan Karakter Indigenous dalam Perspektif Al-Qur'an.

\section{METODE}

Penelitian ini menggunakan pendekatan kualitatif. Data yang diteliti terjaga kualitasnya dan berbentuk kata atau kalimat yang berasal dari berbagai karya-karya ilmiah. Pembahasan penelitian dilakukan dengan deskriptif. Sumber data primer yang digunakan adalah ayat-ayat Alquran yang memiliki kesamaan dalam tema pendidikan karakter serta yang sesuai dalam pembahasan, kemudian ditafsirkan dengan merujuk kepada kitab-kitab tafsir Alquran dari berbagai latar belakang seperti tafsir dari Abdullah bin Muhammad bin Abdurahman bin Ishaq Al-Sheikh (2000), Jalaluddin Muhammad Ibn Ahmad Al-Mahalli (2009), Abdul Malik Abdul Karim Amrullah (2000), Muhammad Quraish Shihab (2005), dan Lajnah Pentashihan Mushaf Alquran (2010), kemudian untuk redaksi hadis, penulis mengutamakan pengutipan dari al-Kutub al-Tis'ah (kumpulan kitab hadis dari 9 imam: al-Bukhari, Muslim, Abu Daud, al-Tirmidzi, alNasa'i, Ibnu Majah, Ahmad, Malik, dan al-Darimi) yang bisa dibaca melalui Lidwa Pustaka i-Software Kitab 9 Imam Hadits, CD-Room.

Sedangkan sumber data sekunder yang digunakan dalam penelitian ini, berfungsi sebagai bahan referensi penting dan untuk memperluas cakupan wawasan pembahasan permasalahan penelitian. Sumber data sekunder terdiri atas karya-karya penelitian ilmiah terdahulu yang relevan, antara lain berupa buku-buku ilmiah yang membahas kajian tentang pendidikan karakter dalam berbagai sudut pandang/perspektif dari bidangbidang ilmu pengetahuan.

Metode tafsir Alquran yang dipakai untuk menganalisis data dalam penelitian ini yaitu Metode Tafsir al-Maudlu'iy (LPMA, 2012: xix-xx). Metode Tafsir al-Maudlu'iy dipilih dalam penelitian ini, dikarenakan metode ini dapat digunakan sebagai penggali permasalahan penelitian dalam upaya menyusun konsep pendidikan karakter indigenous dalam perspektif Alquran secara lebih komprehensif. Langkah-langkah yang dilakukan dalam memakai metode Tafsir alMaudlu'iy yaitu (Rosidin, 2015: 628): 1) melakukan identifikasi ayatayat dalam Alquran yang berkaitan dengan tema permasalahan penelitian, disesuaikan dengan term atau terminology kata yang 
terkandung dalam surat dan ayat Alquran; 2) mengelompokkan ayatayat Alquran berdasarkan tempat turunnya ayat di Makkah atau di Madinah, dengan maksud mengetahui frekuensi dan posisi penyebaran "term" yang tersebar di Makkah atau di Madinah; 3) menyusun surat dan ayat yang sesuai dengan term berdasarkan asbabun nuzul surat dan ayat tersebut dengan tujuan agar (al-Qattan, 2015: 108112): a) memahami kandungan, b) memperjelas maksud, c) mengetahui batasan-batasan hukum, dan d) menyingkap kesamaran arti yang tersembunyi; 4) mengetahui munasabah (korelasi/ hubungan) antara surat-surat dan ayat-ayat Tabel 1. Fokus Intisari Karakter tersebut dalam Alquran yang termasuk di dalam "term" penelitian; dan 5) melengkapi pembahasan dengan hadis-hadis yang relevan, bersamaan dengan melakukan analisis secara tematik dan menyeluruh berdasarkan term, serta dengan menganalisis tafsir Alquran yang berkaitan dengan hal dimaksud.

\section{HASIL DAN PEMBAHSAN \\ Hasil}

Hasil dari penelitian ini yaitu terbentuknya perumusan konsep dan model implementasi pendidikan karakter indigenous dalam perspektif Alquran yang digambarkan dalam bentuk tabulasi-tabulasi berikut.

\section{Fokus Intisari Karakter}

Konsep Pendidikan Karakter Indigenous dalam Perspektif Alquran

\begin{tabular}{cccccc}
\hline Karakter Indigenous & \multicolumn{2}{c}{ Karakter Indigenous } & \multicolumn{2}{c}{ Karakter Indigenous } \\
Religius & Cinta Tanah Air & \multicolumn{2}{c}{ Intelektualitas } \\
Karakter & Karakter & Karakter & Karakter & Karakter & Karakter \\
Indigenou & Indigenous & Indigenou & Indigenous & Indigenous & Indigenous \\
s Religius & Religius & s Cinta & Cinta & Intelektualita & Intelektualita \\
Taqwa & Fujur & Tanah Air & Tanah Air & s Taqwa & s Fujur \\
(Kebaikan & (Keburukan & Taqwa & Fujur & (Kebaikan) & (Keburukan) \\
) & ) & (Kebaikan & (Keburukan & & \\
& & ) & ) & & \\
\hline
\end{tabular}

Dari tabel 1 tersebut terlihat bahwa fokus intisari karakter dari konsep pendidikan karakter indigenous dalam perspektif Alquran adalah proses mendidik karakter indigenous yang terkait dengan 6 intisari karakter dalam pendidikan karakter di Indonesia seperti yang diuraikan dalam tabel tersebut.
Selain itu hasil analisis penelitian ini adalah tersusunnya paradigma yang menjadi acuan di dalam penyusunan konsep pendidikan karakter indigenous dalam perspektif Alquran ini, seperti digambarkan dalam bentuk tabulasi berikut. 
Tabel 2. Paradigma Konsep Pendidikan Karakter Indigenous dalam Perspektif Alquran

\begin{tabular}{lllll}
\hline \multicolumn{5}{c}{ Paradigma } \\
Konsep Pendidikan Karakter Indigenous & dalam Perspektif Alquran \\
\hline \multicolumn{1}{c}{$\mathbf{1}$} & \multicolumn{2}{c}{$\mathbf{3}$} & $\mathbf{4}$ & $\mathbf{5}$ \\
Universal & Didukung & Memaksimalkan & Memberitahukan Implementasi \\
dan tidak & oleh & karakter taqwa & adanya reward untuk \\
memisahkan & Alquran dan & dan & dan punishment pranikah, \\
antara Ilmu & terintegrasi & menghindar, & atas pilihan pre-natal, \\
Naqliyah, & dengan & meminimalkan & kedua karakter. & golden age \\
Ilmu & Sains dan & karakter fujur & & \\
'Aqliyyah, & Teknolologi & & & \\
Ilmu & & & & \\
'Amaliyyah & & & & \\
\hline
\end{tabular}

Dari tabel 2 dimaksud terlihat bahwa paradigma dari konsep pendidikan karakter indigenous dalam perspektif Alquran terdiri atas 5 bagian seperti yang diuraikan di dalamnya.

Pada penelitian ini juga telah tersusun prinsip dan indikator dari konsep pendidikan karakter indigenous dalam perspektif Alquran yang terbagi dalam 4 bagian, seperti pada penggambaran tabulasi berikut.

Tabel 3. Prinsip dan Indikator Konsep Pendidikan Karakter Indigenous dalam Perspektif Alquran

\section{Prinsip dan Indikator}

Konsep Pendidikan Karakter Indigenous dalam Perspektif Alquran

\begin{tabular}{|c|c|c|c|}
\hline Pondasi & Konten & Penyampaian & Kemampuan \\
\hline $\begin{array}{l}\text { Universal (berlaku } \\
\text { umum). Terinspirasi } \\
\text { dari Q.S. Al-Anbiyâ' } \\
[21]: 107) .\end{array}$ & $\begin{array}{l}\text { Simplify } \\
\text { (memudahkan), } \\
\text { terinspirasi dari Q.S. } \\
\text { Al-A'lâ [87]:8. }\end{array}$ & $\begin{array}{l}\text { Fun (menyenangkan), } \\
\text { terinspirasi dari Q.S. } \\
\text { 'Abasa [80]:32. }\end{array}$ & $\begin{array}{l}\text { Knowing } \\
\text { (pengetahuan), } \\
\text { terinspirasi dari Q.S. } \\
\text { Yusuf [12]:55. }\end{array}$ \\
\hline $\begin{array}{l}\text { Sustainable } \\
\text { (berkesinambungan). } \\
\text { Terinspirasi dari }\end{array}$ & $\begin{array}{l}\text { Understandable } \\
\text { (mudah dipahami), } \\
\text { terinspirasi dari Q.S. }\end{array}$ & $\begin{array}{l}\text { Comfortable (nyaman } \\
\text { tidak terpaksa), } \\
\text { terinspirasi dari Q.S. }\end{array}$ & $\begin{array}{l}\text { Feeling (perasaan), } \\
\text { terinspirasi dari Q.S. } \\
\text { Al-Ra'd [13]:28. }\end{array}$ \\
\hline $\begin{array}{l}\text { Q.S. Alam Nasyrah } \\
\text { [94]:7. }\end{array}$ & Al-Qomar [54]:17. & Al-Nisâ [4]:146. & \\
\hline $\begin{array}{l}\text { Unbounded (tidak } \\
\text { ada batasan), }\end{array}$ & $\begin{array}{l}\text { Similarity (mirip } \\
\text { persoalan kehidupan). }\end{array}$ & $\begin{array}{l}\text { Active (aktif, giat dan } \\
\text { bersemangat), }\end{array}$ & $\begin{array}{l}\text { Talking (perkataan). } \\
\text { Terinspirasi dari Q.S. }\end{array}$ \\
\hline
\end{tabular}


terinspirasi dari Q.S. Terinspirasi dari Q.S. terinspirasi dari Q.S. Ibrahim [14]:24 Ali Imran [3]:37. Al-Baqarah [2]: 155. Ali Imran [3]: 104.

\begin{tabular}{|c|c|c|}
\hline $\begin{array}{l}\text { Multisosiocultural } \\
\text { (untuk semua lapisan } \\
\text { budaya masyarakat), } \\
\text { terinspirasi dari Q.S. } \\
\text { Al-Hujurât [49]: } 13 .\end{array}$ & $\begin{array}{l}\text { Togetherness } \\
\text { (kebersamaan), } \\
\text { terinspirasi dari Q.S. } \\
\text { Al-Mâidah [5]: } 2 \text {. }\end{array}$ & $\begin{array}{l}\text { Doing (perbuatan), } \\
\text { terinspirasi dari Q.S. } \\
\text { Al-Nahl [16]:90. } \\
\text { Inspiring } \\
\text { (menginspirasi, } \\
\text { terinspirasi dari Q.S. } \\
\text { Al-Syams [91]: 7-10. }\end{array}$ \\
\hline
\end{tabular}

Dari tabel 3 dimaksud terlihat bahwa prinsip dan indikator dari konsep pendidikan karakter indigenous dalam perspektif Alquran, terdiri atas: 1) pondasi, 2) konten, 3) penyampaian, dan 4) kemampuan. Kesemuanya terdiri atas 4 komponen seperti yang diuraikan dalam tabel tersebut.

Tabel 4. Proses Pembelajaran Konsep Pendidikan Karakter Indigenous dalam Perspektif Alquran

\section{Proses Pembelajaran}

\section{Konsep Pendidikan Karakter Indigenous dalam Perspektif Alquran}

\section{Perhatian Retensi Produk Motivasi}

Proses pembelajaran Proses pembelajaran Proses pembelajaran Proses pembelajaran agar mampu agar mampu agar mampu agar mampu melakukan proses melakukan proses melakukan proses melakukan proses mengalokasikan terjadinya "retensi" "perhatian" terhadap penyimpanan informasi yang ingatan tentang per masuk tentang karakter kebaikan karakter kebaikan dan keburukan, dan keburukan, terinspirasi dari Q.S. terinspirasi dari Q.S. Al-Najm [53]-31. Al-Baqarah [2]: 148. Disebut dengan Disebut dengan istilah "proses istilah "proses pembelajaran" pembelajaran" "ihsan". "istabaqa".
Hasil penelitian lainnya adalah tersusunnya proses pembelajaran dari konsep pendidikan karakter indigenous dalam perspektif Alquran, seperti dalam tabulasi berikut. 
Dari tabel 4 dimaksud terlihat bahwa proses pembelajaran dari konsep pendidikan karakter indigenous dalam perspektif Alquran terdiri atas 4 komponen pembelajaran, seperti: 1) perhatian, 2) retensi, 3) produk, dan 4) motivasi.

Hasil analisis penelitian yang lainnya adalah terungkap adanya karakter indigenous religius, cinta tanah air, intelektualitas dalam perspektif Alquran dari para nabi, antara lain: Nabi Adam a.s., Nabi Ibrahim a.s., dan Nabi Muhammad saw., yaitu:

1. Karakter indigenous Nabi Adam a.s., dalam perspektif Alquran terdiri atas:

a. Karakter indigenous religius taqwa (kebaikan) Nabi Adam a.s. dalam perspektif Alquran, yakni: 1) Taat kepada Allah (Q.S. 7/19; 2/35; 3/33); 2) Mau langsung bertaubat mengubah kesalahan (Q.S. $7 / 23 ; \quad 20 / 122 ; \quad 2 / 37) ; \quad 3)$ Mengakui keesaan Allah (Monotheism) (Q.S. 7/173); 4) Takut kepada Allah (Q.S. 19/58); 5) Bertakwa kepada Allah (Q.S. 4/1); 6) Ikhlas tidak menerima upah dalam tolong menolong sesama (Q.S. 4/1); 7) Selalu bersilaturahim (Q.S. 4/1), 8) Berkeyakinan agama Tauhid (Q.S. 23/52); 9) Pernah tergoda bujuk rayu setan namun segera mengingat Allah dan bertaubat kepada Allah (Q.S. 7/20-22; 20/117; 20/120; 20/121; 2/36); dan 10) Pernah lalai/lupa (nasiya) namun segera mengingat Allah dan bertaubat kepada Allah (Q.S. 20/115). Selain itu Nabi Adam a.s. tidak memiliki karakter indigenous religius fujur (keburukan).

b. Karakter indigenous cinta tanah air taqwa (kebaikan) Nabi Adam a.s. dalam perspektif Alquran, yakni kepemimpinan (leadership) (Q.S. 19/58). Selain itu Nabi Adam a.s. tidak memiliki karakter indigenous cinta tanah air fujur (keburukan).

c. Karakter indigenous intelektualitas taqwa (kebaikan) Nabi Adam a.s. dalam perspektif Alquran, yakni: 1) Rendah hati (Q.S. 38/71); 2) Mulia (Q.S. 38/72$77 ; \quad 7 / 11 ; \quad 7 / 12 ; \quad 20 / 116$; 20/118; 20/119; 17/61; 15/26; 18/50; 2/34); 3) Mandiri (Q.S. 6/98; 3/59; 4/1); 4) Mau belajar (Q.S. 2/31); 5) Mau menghafal (Q.S. 2/31); 6) Mudah mengingat (Q.S. 2/31); 7) Percaya diri (Q.S. 2/31); dan 8) Teliti (Q.S. 2/33). Selain itu tidak memiliki karakter indigenous intelektualitas fujur (keburukan).

2. Karakter indigenous Nabi Ibrahim a.s. dalam perspektif Alquran terdiri atas:

a. Karakter indigenous religius taqwa (kebaikan) Nabi Ibrahim a.s. dalam perspektif Alquran, yakni: 1) Patuh kepada Allah (Q.S. 19/58, 2/128, 2/132, 2/133, 2/136);

2) Taat kepada Allah (Q.S. 26/69, 11/75, 12/38, 29/16); 3) Mau menerima ketetapan 
dari Allah (Q.S. 11/76); 4) Meng-Esa-kan Allah (Monotheism) (Q.S. 6/74, 6/161, 42/13, 43/26, 16/120, 16/123, 14/35, 21/60, 2/135, 3/65, 22/26); 5) Yakin dan beriman pada Allah (Q.S. 6/75, 37/83, 42/13, 3/68, 22/78); 6) Berbuat baik (Q.S. 37/109, 37/110); 7). Bertakwa dan tawakal kepada Allah (Q.S. 42/13, 29/16, 22/78, 21/69); 8) Salih (Q.S. 2/125, 2/126, 2/127, 2/130); 9) Berserah diri kepada Allah dan tidak musyrik (Q.S. 3/67, 3/84, $3 / 95)$

Menyampaikan kebenaran (Q.S. 33/7); 11) Ikhlas mengerjakan kebaikan dan berusaha disayang Allah (Q.S. 4/125); 12)

Berkeyakinan agama tauhid (Q.S. 4/163); 13) Menerima petunjuk Allah (Q.S. 57/26); dan 14) Memohon ampunan bagi orang musyrik kepada Allah (Namun oleh Allah diingatkan untuk tidak melakukannya kembali) (Q.S. 60/4), elain itu, tidak memiliki karakter indigenous religius fujur (keburukan).

b. Karakter indigenous cinta tanah air taqwa (kebaikan) Nabi Ibrahim a.s. dalam perspektif Alquran, yakni: 1) Tegar dan visioner (Q.S. 38/45, 2/124, 21/51, 21/66); 2) Leadership (Q.S. 19/58, 2/128, 2/132, 2/133, 2/136);

3) Komitmen (Q.S. 26/69, $11 / 75, \quad 12 / 38, \quad 29 / 16)$; 4) Berpegang pada kebenaran (hanif) (Q.S. 16/120, 16/123); 5) Pandai berstrategi (Q.S.
21/62); 6) Pemberani dan pantang menyerah (Q.S. 21/66, 21/67, 21/68); dan 7) Peduli dan bertanggung jawab (Q.S. 2/125, 2/126, 2/127, 2/130). Selain itu tidak memiliki karakter indigenous cinta tanah air fujur (keburukan).

c. Karakter indigenous intelektualitas taqwa (kebaikan) Nabi Ibrahim a.s. dalam perspektif Alquran, yakni: 1) Menepati janji (waffâ) (Q.S. 53/37); 2) Cerdas (Q.S. 38/45, 2/124, 21/51, 21/66); 3) Jujur (Q.S. 19/41); 4) Menghargai, ramah, baik hati, suka memberi (Q.S. 11/69, 51/24, $51 / 25, \quad 51 / 26, \quad 51 / 27) ; 5$ ) Santun, lembut (Q.S. 11/75, 9/114); 6) Tinggi Derajatnya (Q.S. 6/83); 7) Memuliakan tamu (Q.S. 51/24, 51/25, 51/26, 51/27); 8) Teladan (Q.S. 16/120, 16/123); 9) Pandai berstrategi (Q.S. 21/62); 10) Bertanggung jawab (Q.S. 2/125, 2/126, 2/127, 2/130); 11) Rasional (Q.S. 2/258); 12) Rasa ingin tahu dan tenang (Q.S. 2/260); 13) Mulia (Q.S. 3/33, 4/54, 2/124); dan 14) Istiqomah (Q.S. 3/67, 3/84, 3/95); 15). Mawas diri (Q.S. 4/125). Selain itu tidak memiliki karakter indigenous intelektualitas fujur (keburukan).

3. Karakter indigenous Nabi Muhammad a.s. dalam perspektif Alquran terdiri atas:

a. Karakter indigenous religius taqwa (kebaikan) Nabi 
Muhammad saw. dalam perspektif Alquran, yakni: 1) Berakhlak mulia (Q.S. 68/4); 2) Sabar (Q.S. 68/48; 68/51; 16/127); 3) Menyampaikan peringatan tentang hukumhukum Allah (Q.S. 53/56; 7/184; 36/11; 36/70; 35/23; $35 / 24 ; 26 / 194 ; 6 / 33 ; 34 / 28$; $34 / 46 ; 46 / 9 ; 21 / 45 ; 2 / 119$; $33 / 45 ; \quad 33 / 46 ; \quad / 67)$; 4) Menyampaikan tentang keEsa-an Allah (Q.S. 38/65; 7/184; 36/70; 35/23; 35/24; 26/194; 34/28; 34/46); 5) Ikhlas tidak menerima dalam menyampaikan dakwah hukum-hukum Allah (Q.S. 38/86); 6) Membenarkan halhal ghaib yang datang dari Allah (Q.S. 19/41); 7) Senantiasa membaca Alquran tidak tergesa-gesa (Q.S. 20/114); 8) Senantiasa berdo'a memohon tambahan ilmu pengetahuan (Q.S. 20/114); 9). Melaksanakan hukum-hukum Allah (Q.S. 28/85); 10) Taat pada Allah (Q.S. 17/76); 11) Mulia (Q.S. $15 / 72 ; 2 / 253 ; 33 / 56) ; 12$ ) Tidak pernah ragu dalam menjalankan hukum-hukum Allah (Q.S. 6/114); 13) Selalu melakukan kebenaran sesuai hukum-hukum Allah (Q.S. 37/37); 14) Menyusun kekuatan untuk menegakkan hukum-hukum Allah (Q.S. 37/174); 15) Bertaqwa kepada Allah (Q.S. 39/33); 16) Selalu bertasbih kepada Allah (Q.S. 39/75); 17) Tidak menyekutukan Allah (Q.S. 40/66); 18) Tunduk patuh kepada Allah (Q.S. 40/66);
19) Menegaskan bahwa Allah tidak memiliki keturunan (Q.S. 43/81); 20) Menyembah hanya kepada Allah (Q.S. 43/84); 21) Menyampaikan kebenaran Alquran dari Allah (Q.S. 46/8; 46/10; 5/15; 5/67); 22) Beriman kepada Allah (Q.S. 3/114); 23) Beriman kepada hari kiamat (Q.S. 3/114); 23); 24) Menyuruh kebaikan (Q.S. 3/114); 23); 25) Mencegah kemungkaran (Q.S. 3/114); 23); 26) Bersegera mengerjakan kebaikan sesuai hukum Allah (Q.S. 3/114); 23); 27) Lemah lembut (Q.S. 3/159); 28) Memohonkan ampun kepada Allah (Q.S. 3/159); 29) Bertawakal kepada Allah (Q.S. 3/159); 30). Selalu mengharapkan rahmat Allah (Q.S. 33/21); 31) Meyakini kedatangan hari kiamat (Q.S. 33/21); 32) Selalu menyebut Allah (Q.S. 33/21); 33). Tidak takut pada orang kafir dan munafik Berani (Q.S. 33/48); 34) Memohonkan ampun kepada Allah (Q.S. 24/62); 35) Keras menegakkan hukum-hukum Allah terhadap orang kafir; 36) Lemah lembut kepada sesama (Q.S. 48/29); dan 37) Meyakini akan perlindungan Allah (Q.S. 9/40); 38). Pernah bermuka masam (namun ditegur Allah, setelah itu tidak pernah melakukannya lagi) (Q.S. 80/1-6). Selain itu Nabi Muhammad saw. tidak memiliki karakter indigenous religius fujur (keburukan). 
b. Karakter indigenous cinta tanah air taqwa (kebaikan) Nabi Muhammad saw. dalam perspektif Alquran, yakni: 1) Kepemimpinan (Leadership) (Q.S. 32/23, 24); 2) Tegas (Q.S. 2/76); 3) Menyuruh kebaikan (Q.S. 3/114); 4) Mencegah kemungkaran (Q.S. 3/114); 5) Memaafkan dalam urusan dunia (Q.S. 3/159); 6) Bermusyawarah dalam urusan dunia (Q.S. 3/159); dan 7) Menyenangkan (Q.S. 33/45). Selain itu Nabi Muhammad tidak memiliki karakter indigenous cinta tanah air fujur (keburukan).

c. Karakter indigenous intelektualitas taqwa (kebaikan) Nabi Muhammad saw. dalam perspektif Alquran, yakni: 1) Berakhlak mulia (Q.S. 68/4); 2) Sabar (Q.S. 68/48; 68/51; 16/127); 3) Senantiasa berdo'a memohon tambahan ilmu pengetahuan (Q.S. 20/114); 4) Mulia (Q.S. 15/72; 2/253; 33/56); 5) Tegas (Q.S. 2/76); 6) Menyuruh kebaikan (Q.S. 3/114); 7) Mencegah kemungkaran (Q.S. 3/114); 8) Lemah lembut (Q.S. 3/159);

9) Memaafkan dalam urusan dunia (Q.S. 3/159); 10)

Bermusyawarah dalam urusan dunia (Q.S. 3/159); 11) Jujur (Q.S. 33/45); 12) Dapat dipercaya (Q.S. 33/45); 13) Menyenangkan (Q.S. 33/45); dan 14) Lemah lembut kepada sesama (Q.S. 48/29). Selain itu, Nabi Muhammad tidak memiliki karakter indigenous intelektualitas fujur (keburukan).

Selain terungkapnya seperti hal dimaksud tersebut, dalam penelitian ini juga terungkap karakter indigenous manusia dalam perspektif Alquran, yakni: 1) Karakter indigenous religius taqwa (kebaikan) manusia; 2) Karakter indigenous religius fujur (keburukan) manusia; 3) Karakter indigenous cinta tanah air taqwa (kebaikan) manusia; 4) Karakter indigenous cinta tanah air fujur (keburukan) manusia; 5) Karakter indigenous intelektualitas taqwa (kebaikan) manusia; dan 6) Karakter indigenous intelektualitas fujur (keburukan) manusia. Uraian dimaksud dapat dilihat pada tabel 5, tabel 6, dan tabel 7 berikut.

Tabel 5. Karakter Indigenous Religius Taqwa (Kebaikan) Manusia dalam Perspektif Alquran

\begin{tabular}{cll}
\hline No. & \multicolumn{1}{c}{$\begin{array}{c}\text { Kandungan Karakter Indigenous } \\
\text { Religius Taqwa (Kebaikan) }\end{array}$} & \multicolumn{1}{c}{ Surat \& Ayat } \\
\hline 1 & Taat/Submisif & $8 / 46 ; 2 / 21 ; 1 / 5$ \\
2 & Sabar & $8 / 66$ \\
3 & Empati & $33 / 29$ \\
4 & Pemurah & $57 / 18$ \\
5 & Tawakal & $12 / 67 ; 14 / 12 ; 39 / 38 ; 3 / 159$ \\
6 & Taqwa (rasa takut) & $2 / 177 ; 8 / 34 ; 13 / 35 ; 25 / 15 ; 39 / 33 ;$
\end{tabular}




\begin{tabular}{cll}
7 & Senang memberi & $47 / 15$ \\
8 & Ikhlash & $2 / 3$ \\
9 & Selalu memohon ampun & $12 / 24 ; 15 / 40 ; 37 / 40 ; 37 / 74$ \\
10 & Bersyukur & $51 / 18$ \\
11 & Menerima saran/bijak & $86 / 3$ \\
12 & Pemaaf & $2 / 206$ \\
13 & Egaliter & $3 / 159$ \\
14 & Tenang & $49 / 13$ \\
\hline
\end{tabular}

Tabel 6. Karakter Indigenous Cinta Tanah Air Taqwa (Kebaikan) Manusia dalam Perspektif Alquran

\begin{tabular}{|c|c|c|}
\hline No. & $\begin{array}{c}\text { Kandungan Karakter Indigenous Cinta } \\
\text { Tanah Air Taqwa (Kebaikan) } \\
\end{array}$ & Surat \& Ayat \\
\hline 1 & Konsisten & $8 / 45$ \\
\hline 2 & Mendunia & $17 / 70 ; 49 / 13$ \\
\hline 3 & Aktif (mujaahidin) & $4 / 95 ; 47 / 31$ \\
\hline 4 & $\begin{array}{l}\text { Obyektif - orang-orang yang adil } \\
\text { (muQ.S.itiin) }\end{array}$ & $5 / 42 ; 49 / 9 ; 60 / 8$ \\
\hline 5 & $\begin{array}{l}\text { Obyektif }- \text { orang-orang yang benar } \\
\text { (saadiquun) }\end{array}$ & $49 / 15 ; 14 / 17$ \\
\hline 6 & Independen & $8 / 53$ \\
\hline 7 & Kemampuan memimpin & $27 / 23$ \\
\hline 8 & $\begin{array}{l}\text { Lebih merdeka / membela diri } \\
\text { (yantasyiruun) }\end{array}$ & $42 / 39$ \\
\hline
\end{tabular}

Tabel 7. Karakter Indigenous Intelektualitas Taqwa (Kebaikan) Manusia dalam Perspektif Alquran

\begin{tabular}{lll}
\hline No. & \multicolumn{1}{c}{$\begin{array}{c}\text { Kandungan Karakter Indigenous } \\
\text { Intelektualitas } \\
\text { Taqwa (Kebaikan) }\end{array}$} & \multicolumn{1}{c}{ Surat \& Ayat } \\
\hline 1 & \multicolumn{1}{c}{ Kompetitif } & $18 / 30$ \\
2 & Logis (ya'qiluun) & $2 / 164 ; 13 / 4 ; 16 / 12 ; 29 / 35$ \\
3 & Independen & $8 / 53$ \\
4 & Petualang (intasyara) & $62 / 9$ \\
5 & Komunikatif & $3 / 159$ \\
6 & Keseimbangan rasio dan rasa & $49 / 9 ; 49 / 10$ \\
7 & Lebih bebas bicara & $55 / 3 ; 55 / 4$
\end{tabular}




\begin{tabular}{clc}
8 & Visioner & $3 / 104$ \\
9 & Responsif & $3 / 114$ \\
10 & Progressif & $17 / 36$ \\
11 & Produktif & $16 / 97$ \\
12 & Kreatif & $13 / 11$ \\
13 & Koperatif & $3 / 103$ \\
\hline
\end{tabular}

Tabel 5, 6, dan 7 di atas menunjukkan karakter indigenous religius, cinta tanah air, intelektualitas taqwa (kebaikan) dalam perspektif Alquran, sedangkan karakter indigenous religius, cinta tanah air, intelektualitas fujur (keburukan) manusia dalam perspektif Alquran adalah merupakan kebalikan berlawanan dari karakter indigenous taqwa (kebaikan) dengan berdasarkan suatu konsep dalam ilmu mantiq yang disebut dengan hukum kategori kalimat qadhiyah syarthiyah munfashilah mani'ah jam'in wa khuluw (haqiqiyah) ijabi (suatu Perspektif Alquran

\begin{tabular}{|c|c|c|c|}
\hline No. & $\begin{array}{l}\text { Karakter Indigenous } \\
\text { Religius Taqwa } \\
\text { (Kebaikan) }\end{array}$ & $\begin{array}{c}\text { Surat \& Ayat yang } \\
\text { Mengandung } \\
\text { Karakter Indigenous Religius } \\
\text { Taqwa (Kebaikan) }\end{array}$ & $\begin{array}{c}\text { Karakter Indigenous } \\
\text { Religius Fujur } \\
\text { (Keburukan) }\end{array}$ \\
\hline 1 & Taat/Submisif & $8 / 46 ; 2 / 21 ; 1 / 5$ & Penentang \\
\hline 2 & Sabar & $8 / 66$ & Emosional \\
\hline 3 & Empati & $33 / 29$ & Antipati \\
\hline 4 & Pemurah & $57 / 18$ & Kikir \\
\hline 5 & Tawakal & $12 / 67 ; 14 / 12 ; 39 / 38 ; 3 / 159$ & Pemberontak \\
\hline 6 & Taqwa (rasa takut) & $\begin{array}{l}2 / 177 ; 8 / 34 ; 13 / 35 ; 25 / 15 ; 39 / 33 ; \\
47 / 15\end{array}$ & Melawan \\
\hline 7 & Senang memberi & $2 / 3$ & Pelit \\
\hline 8 & Ikhlash & $12 / 24 ; 15 / 40 ; 37 / 40 ; 37 / 74$ & Pamrih \\
\hline 9 & $\begin{array}{l}\text { Selalu memohon } \\
\text { ampun }\end{array}$ & $51 / 18$ & Tidak merasa bersalah \\
\hline 10 & Bersyukur & $86 / 3$ & Kufur \\
\hline 11 & Menerima saran/bijak & $2 / 206$ & Egois \\
\hline
\end{tabular}




\begin{tabular}{llll}
12 & Pemaaf & $3 / 159$ & Pendendam \\
13 & Egaliter & $49 / 13$ & Primordial \\
14 & Tenang & $33 / 35 ; 66 / 5 ; 89 / 27$ & Rusuh \\
\hline
\end{tabular}

Tabel 9. Karakter Indigenous Cinta Tanah Air Fujur (Keburukan) Manusia Dalam Perspektif Alquran

\begin{tabular}{|c|c|c|c|}
\hline No. & $\begin{array}{l}\text { Karakter Indigenous } \\
\text { Cinta Tanah Air } \\
\text { Taqwa (Kebaikan) }\end{array}$ & $\begin{array}{c}\text { Surat \& Ayat yang } \\
\text { Mengandung } \\
\text { Karakter Indigenous Cinta } \\
\text { Tanah Air Taqwa (Kebaikan) }\end{array}$ & $\begin{array}{l}\text { Karakter Indigenous } \\
\text { Cinta Tanah Air } \\
\text { Fujur (Keburukan) }\end{array}$ \\
\hline 1 & Konsisten & $8 / 45$ & Inkonsisten \\
\hline 2 & Mendunia & $17 / 70 ; 49 / 13$ & Pola Pikir Sempit \\
\hline 3 & Aktif (mujaahidin) & $4 / 95 ; 47 / 31$ & Pasif \\
\hline 4 & $\begin{array}{l}\text { Obyektif }- \text { orang- } \\
\text { orang yang adil } \\
(\text { muQ.S.itiin })\end{array}$ & $5 / 42 ; 49 / 9 ; 60 / 8$ & Subyektif - curang \\
\hline 5 & $\begin{array}{l}\text { Obyektif - } \text { orang- } \\
\text { orang yang benar } \\
\text { (saadiquun) }\end{array}$ & $49 / 15 ; 14 / 17$ & $\begin{array}{l}\text { Subyektif } \\
\text { berprasangka }\end{array}$ \\
\hline 6 & Independen & $8 / 53$ & Memihak \\
\hline 7 & $\begin{array}{l}\text { Kemampuan } \\
\text { memimpin }\end{array}$ & $27 / 23$ & Pengekor \\
\hline 8 & $\begin{array}{l}\text { Lebih merdeka / } \\
\text { membela diri } \\
\text { (yantasyiruun) }\end{array}$ & $42 / 39$ & Terbelenggu \\
\hline
\end{tabular}

Tabel 10. Karakter Indigenous Intelektualitas Fujur (Keburukan) Manusia Dalam Perspektif Alquran

\begin{tabular}{|c|c|c|c|}
\hline No. & $\begin{array}{c}\text { Karakter Indigenous } \\
\text { Intelektualitas } \\
\text { Taqwa (Kebaikan) }\end{array}$ & $\begin{array}{c}\text { Surat \& Ayat yang } \\
\text { Mengandung } \\
\text { Karakter Indigenous } \\
\text { Intelektualitas Taqwa } \\
\text { (Kebaikan) } \\
\end{array}$ & $\begin{array}{c}\text { Karakter Indigenous } \\
\text { Intelektualitas } \\
\text { Fujur (Keburukan) }\end{array}$ \\
\hline 1 & Kompetitif & $18 / 30$ & Mudah menyerah \\
\hline 2 & Logis (ya'qiluun) & $2 / 164 ; 13 / 4 ; 16 / 12 ; 29 / 35$ & Irasional \\
\hline 3 & Independen & $8 / 53$ & Memihak \\
\hline 4 & Petualang (intasyara) & $62 / 9$ & Pembelenggu \\
\hline 5 & Komunikatif & $3 / 159$ & Kaku \\
\hline 6 & $\begin{array}{l}\text { Keseimbangan rasio } \\
\text { dan rasa }\end{array}$ & $49 / 9 ; 49 / 10$ & Irasional \\
\hline 7 & Lebih bebas bicara & $55 / 3 ; 55 / 4$ & Penghambat \\
\hline 8 & Visioner & $3 / 104$ & Terbatas \\
\hline 9 & Responsif & $3 / 114$ & Lambat \\
\hline 10 & Progressif & $17 / 36$ & Menunda \\
\hline
\end{tabular}




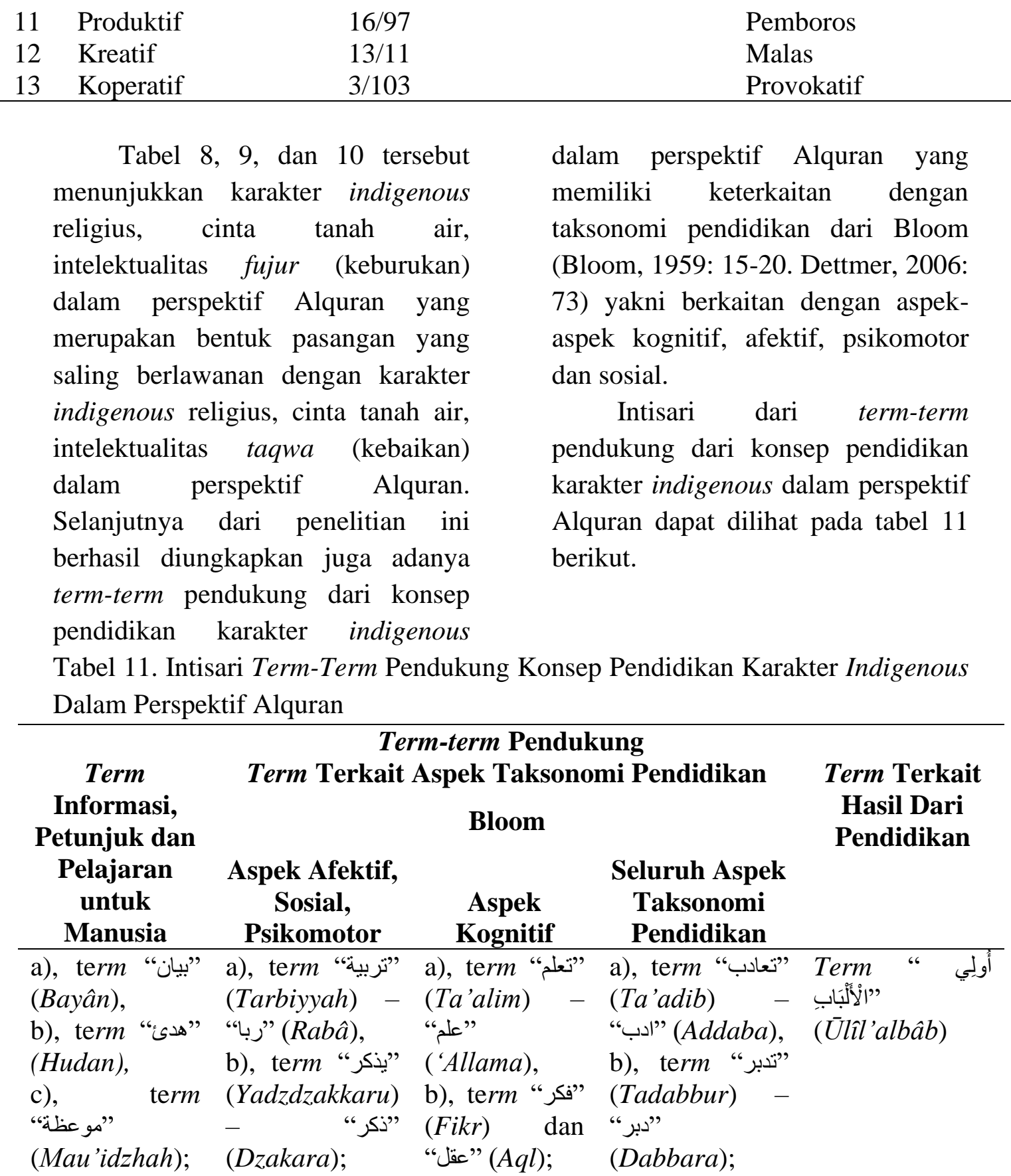




\begin{tabular}{|c|c|c|c|c|}
\hline $\begin{array}{l}\text { Mendidik } \\
\text { karakter } \\
\text { manusia untuk } \\
\text { membangun } \\
\text { Integritas } \\
\text { Alamiah } \\
\text { (Indigenous } \\
\text { Integrity), } \\
\text { yakni; } \\
\text { Integritas } \\
\text { alamiah dalam } \\
\text { diri untuk } \\
\text { meyakini dan } \\
\text { berserah diri } \\
\text { terhadap } \\
\text { informasi yang } \\
\text { merupakan } \\
\text { petunjuk, } \\
\text { pelajaran } \\
\text { dalam } \\
\text { menjalankan } \\
\text { kehidupan } \\
\text { serta rahmat } \\
\text { dari Allah } \\
\text { Swt. Tuhan } \\
\text { Yang Maha } \\
\text { Pencipta. }\end{array}$ & $\begin{array}{l}\text { Mendidik } \\
\text { karakter } \\
\text { manusia untuk } \\
\text { membangun } \\
\text { Integritas } \\
\text { Afektif, Sosial } \\
\text { dan } \\
\text { Psikomotor } \\
\text { (Affective, and } \\
\text { Social an } \\
\text { Psychomotor } \\
\text { Integrity) dan } \\
\text { membangun } \\
\text { Integritas } \\
\text { Bersikap dan } \\
\text { Berperilaku } \\
\text { Afektif, Sosial } \\
\text { dan } \\
\text { Psikomotor } \\
\text { (Affective, } \\
\text { Social and } \\
\text { Psychomotor } \\
\text { Attitude and } \\
\text { Behaviour } \\
\text { Integrity). }\end{array}$ & $\begin{array}{l}\text { Mendidik } \\
\text { karakter } \\
\text { manusia } \\
\text { untuk } \\
\text { membangun } \\
\text { Integritas } \\
\text { Kognitif } \\
\text { (Cognitive } \\
\text { Integrity) dan } \\
\text { Mendidik } \\
\text { karakter } \\
\text { manusia } \\
\text { untuk } \\
\text { membangun } \\
\text { Integritas } \\
\text { Bersikap dan } \\
\text { Berperilaku } \\
\text { sesuai aspek } \\
\text { Kognitif } \\
\text { (Cognitive } \\
\text { Attitude and } \\
\text { Behavior } \\
\text { Integrity). }\end{array}$ & $\begin{array}{l}\text { Mendidik } \\
\text { karakter } \\
\text { manusia untuk } \\
\text { membangun } \\
\text { Integritas } \\
\text { Afektif, } \\
\text { Kognitif, } \\
\text { Sosial, } \\
\text { Psikomotor } \\
\text { (Affective, } \\
\text { Cognitive, } \\
\text { Social and } \\
\text { Psychomotor } \\
\text { Integrity) dan } \\
\text { Mendidik } \\
\text { karakter } \\
\text { manusia untuk } \\
\text { membangun } \\
\text { Integritas } \\
\text { Bersikap dan } \\
\text { Berperilaku } \\
\text { sesuai aspek- } \\
\text { aspek; Kognitif, } \\
\text { Afektif, Sosial, } \\
\text { Psikomotor } \\
\text { (Affective, } \\
\text { Cognitive, } \\
\text { Social and } \\
\text { Psychomotor } \\
\text { Attitude and } \\
\text { Behaviour } \\
\text { Integrity). }\end{array}$ & $\begin{array}{l}\text { Mendidik } \\
\text { karakter } \\
\text { manusia untuk } \\
\text { membangun } \\
\text { Integritas } \\
\text { bersikap dan } \\
\text { berperilaku } \\
\text { sesuai aspek- } \\
\text { aspek; Kognitif } \\
\text { (kemampuan } \\
\text { yang } \\
\text { menekankan } \\
\text { aspek } \\
\text { intelektual); } \\
\text { Afektif } \\
\text { (kemampuan } \\
\text { yang } \\
\text { menekankan } \\
\text { aspek perasaan } \\
\text { dan emosi); } \\
\text { Sosial } \\
\text { (kemampuan } \\
\text { berperilaku } \\
\text { sosial); } \\
\text { Psikomotor } \\
\text { (kemampuan } \\
\text { yang } \\
\text { menekankan } \\
\text { keterampilan } \\
\text { motorik indera } \\
\text { tubuh). }\end{array}$ \\
\hline
\end{tabular}

Sedangkan pengungkapan temuan yang terakhir dari penelitian ini adalah temuan model implementasi dari konsep pendidikan karakter indigenous dalam perspektif Alquran, yaitu: 1) T: Tunjukkan teladan digabung dengan Qudwah (Keteladanan). Penggabungan model ini untuk membangkitkan sifat alamiah manusia yang lebih suka mencontoh dan meniru suatu perbuatan, serta model qudwah ini lebih universal karena dianggap mampu "berkomunikasi" dengan manusia dari berbagai macam dan tingkat kemampuan intelektualitasnya; 2) A: Arahkan dan berikan bimbingan digabung dengan al-amr (perintah). Penggabungan kedua model ini untuk mengarahkan 
dan membimbing, serta dibarengi dengan perintah (al-amr) yang bermakna sebagai permintaan melakukan suatu hal yang berhubungan dengan kebaikan; 3) D: Dorongan motivasi digabung dengan targhîb

(memotivasi).

Penggabungan kedua model ini untuk memberi efek motivasi seseorang mengikuti atau melakukan apa yang menjadi tujuan pendidikan; 4) Z: Zakiyah (niat murni) digabungkan dengan kisah. Penggabungan kedua model ini untuk menanamkan niat murni yang bersih dan tulus dengan menguraikan suatu kisah kejadian/cerita tentang suatu hal yang berkaitan dengan niat murni dalam melakukan suatu kebaikan. Dalam Alquran banyak digunakan model kisah untuk menguraikan suatu kisah atau kejadian yang bekaitan dengan kisah para nabi, atau kisah-kisah dan kejadian-kejadian lainnya; 5) $\mathrm{K}$ : Kontinuitas atau terus menerus (sustainable) digabungkan dengan pembiasaan ('amilus shalihât). Penggabungan kedua model ini untuk mendidikan secara terus menerus melakukan kebiasaan dalam hal kebaikan; 6) I: Ingatkan digabung dengan tarhîb (larangan). Penggabungan kedua model ini untuk mengingatkan dan berupaya memberi rasa takut agar meninggalkan atau menjauhi suatu perbuatan/pekerjaan yang bertentangan dengan kebaikan; 7) R: Repetisi, pengulangan digabungkan dengan pembiasaan ('amilus shalihât). Penggabungan kedua model ini untuk melakukan pembiasaan yang berulang-ulang tentang kebaikan, sehingga semakin lama semakin dimengerti dan dipahami oleh peserta didik; 8) O: Organisasikan kerja samanya digabungkan dengan dialog dan debat. Penggabungan kedua model ini mengajak diskusi dengan dialog dan perdebatan yang terarah, tertib, saling mengharagai antar peserta didik untuk menggali kemampuan berpikir para peserta didik; dan 9) $\mathrm{H}$ : Hati disentuh (touch the heart) digabungkan dengan kisah. Penggabungan kedua model ini untuk menyentuh hati dengan menguraikan suatu kisah kejadian/cerita tentang suatu hal yang berkaitan dengan kisah mengelola hati.

\section{Pembahasan}

Berdasarkan tabel 1 di atas terlihat bahwa fokus intisari karakter atau pendidikan karakter di Indonesia adalah mendidik karakter-karakter yang berasal dari konsep pendidikan karakter indigenous dalam perspektif Alquran, yakni: 1) Karakter indigenous religius (karakter religius merupakan karakter yang ditunjukkan oleh sikap dan perilaku yang patuh dalam melaksanakan ajaran agama yang dianutnya, toleran terhadap pelaksanaan ibadah agama lain, dan hidup rukun dengan pemeluk agama lain (Hasan, et al., 
2010: 9-10) dalam perspektif Alquran, terdiri atas: a) Karakter indigenous religius taqwa (kebaikan) (karakter sesuai dengan ajaran religius), b) Karakter indigenous religius fujur (keburukan) (karakter berlawanan dengan ajaran religius); 2) Karakter indigenous cinta tanah air (karakter cinta tanah air merupakan karakter yang ditunjukkan dengan cara berpikir, bersikap, dan berbuat yang menunjukkan kesetiaan, kepedulian, dan penghargaan yang tinggi terhadap bahasa, lingkungan fisik, sosial, budaya, ekonomi, dan politik bangsa dalam perspektif Alquran, terdiri atas: a) Karakter indigenous cinta tanah air taqwa (kebaikan) (karakter sesuai dengan kondisi aturan yang berlaku tentang cinta tanah air), b) Karakter indigenous cinta tanah air fujur (keburukan) (karakter yang berlawanan dengan kondisi aturan yang berlaku tentang cinta tanah air); 3) Karakter indigenous intelektualitas dalam perspektif Alquran, terdiri atas: a) Karakter indigenous intelektualitas taqwa (kebaikan) adalah karakter yang sesuai dengan kondisi aturan berlaku berkaitan tentang intelektualitas, b) Karakter indigenous intelektualitas fujur (keburukan) adalah karakter yang berlawanan dengan kondisi aturan yang berlaku berkaitan tentang intelektualitas.

Dari tabel 2 di atas terlihat bahwa paradigma pendidikan karakter indigenous dalam perspektif Alquran terdiri atas: 1) Pendidikan karakter indigenous dalam perspektif Alquran adalah konsep dan model implementasi pendidikan karakter yang universal dan tidak ada pemisahan antara ilmu pengetahuan dan teknologi dengan ilmu agama; 2) Pendidikan karakter indigenous dalam perspektif Alquran adalah konsep dan model implementasi pendidikan karakter yang didukung surat-surat dan ayat-ayat Alquran dalam konteks pendidikan karakter manusia, serta terintegrasi dengan ilmu pengetahuan dan teknologi; 3) Pendidikan karakter indigenous dalam perspektif Alquran adalah konsep dan model implementasi pendidikan karakter yang memberikan fokus pada intisari pendidikan karakter terhadap karakter indigenous religius, cinta tanah air, intelektualitas dalam perspektif Alquran, serta berupaya mengoptimalkan, membangun, mengembangkan karakter indigenous taqwa (kebaikan) dan berupaya meminimalkan atau menghilangkan karakter indigenous fujur (keburukan); 4) Pendidikan karakter indigenous dalam perspektif Alquran adalah konsep dan model implementasi pendidikan karakter yang memiliki konsekuensi dari Allah Swt. mengenai akibat terhadap pilihan dari masing-masing karakter dimaksud, apakah pilihan kepada karakter indigenous taqwa (kebaikan) yang akan mendapatkan 
"reward", ataukah pilihan terhadap karakter indigenous fujur (keburukan) yang akan mendapatkan "punishment"; 5) Pendidikan karakter indigenous dalam perspektif Alquran adalah konsep dan model implementasi pendidikan karakter yang pembahasannya di sini dibatasi yang dimulai dari sejak masa pranikah, masa prenatal, hingga masa golden age, sesuai dengan tahapan perkembangan usia dan disesuaikan dengan kemampuan maupun kompetensi manusia, serta berdasarkan domain tujuan pendidikan dalam taksonomi pendidikan manusia.

Dari tabel 3 dimaksud terlihat bahwa prinsip dan indikator dari konsep pendidikan karakter indigenous dalam perspektif Alquran, terdiri atas: pondasi, konten, penyampaian, dan kemampuan. Masing-masing komponen tersebut terdiri atas: A. Prinsip dan indikator "pondasi" terdiri atas: 1) universal (berlaku umum), terinspirasi dari Q.S. AlAnbiyâ' [21]:107); 2) sustainable (berkesinambungan), terinspirasi dari Q.S. Alam Nasyrah [94]:7; 3) unbounded (tidak ada batasan), terinspirasi dari Q.S. Ali Imran [3]:37; B. Prinsip dan indikator "konten" terdiri atas: 1) simplify (memudahkan), terinspirasi dari Q.S. Al-A'lâ [87]:8; 2) understandable (mudah dipahami), terinspirasi dari Q.S. Al-Qomar [54]:17; 3) similarity (mirip persoalan kehidupan), terinspirasi dari Q.S. Al-Baqarah [2]:55; 4) multisosiocultural (untuk semua lapisan budaya masyarakat), terinspirasi dari Q.S. Al-Hujurât [49]:13; C. Prinsip dan indikator "penyampaian" terdiri atas: 1) fun (menyenangkan), terinspirasi dari Q.S. 'Abasa [80]:32; 2) comfortable (nyaman tidak terpaksa), terinspirasi dari Q.S. Al-Nisâ [4]:146; 3) active (aktif, giat dan bersemangat), terinspirasi dari Q.S. Ali Imran [3]:104; 4) togetherness (kebersamaan), terinspirasi dari Q.S. Al-Mâidah [5]:2; D. Prinsip dan indikator "kemampuan" terdiri atas: 1) knowing (pengetahuan), terinspirasi dari Q.S. Yusuf [12]:55.; 2) feeling (perasaan), terinspirasi dari Q.S. Al-Ra'd[13]:28; 3) talking (perkataan), terinspirasi dari Q.S. Ibrahim[14]:24; 4) doing (perbuatan), terinspirasi dari Q.S. AlNahl[16]:90; dan 5) inspiring (menginspirasi), terinspirasi dari Q.S. Al-Syams[91]:7-10.

Dari tabel 4 terlihat bahwa proses pembelajaran dari konsep pendidikan karakter indigenous dalam perspektif Alquran terdiri atas 4 komponen pembelajaran, yaitu perhatian, retensi, produk, dan motivasi. Keempat komponen itu berdasarkan teori Albert Bandura tentang pembelajaran observasional, bagian dari teori kognitif sosial yang didasarkan pada empat proses sebagai kunci keberhasilan pembelajaran observasional 
(Santrock, 2014:195), kemudian ditinjau dalam perspektif Alquran.

Uraian isi dari keempat komponen tersebut sebagai berikut.

1. Untuk proses pembelajaran agar mampu melakukan proses mengalokasikan "perhatian" siswa supaya tertarik terhadap informasi yang masuk tentang karakter kebaikan dan keburukan serta dampak yang ditimbulkannya. Ini ditemukan terinspirasi dari surat dan ayat Alquran yang mengandung term "istabaqa" yang berarti "berlomba" antara lain terdapat dalam Alquran surat Al-Baqarah [2]: 148.

2. Untuk proses pembelajaran agar mampu melakukan proses melaksanakan terjadinya "retensi" atau penyimpanan ingatan tentang karakter kebaikan dan keburukan serta dampak yang ditimbulkannya. Ini ditemukan terinspirasi dari surat dan ayat Alquran yang mengandung term "ihsan" yang berarti "berbuat baik" antara lain terdapat dalam Alquran surat AlNajm [53]-31.

3. Untuk proses pembelajaran agar mampu melakukan proses membangun suatu bentuk "produk" pemodelan yang membantu proses mengeluarkan hasil "retensi" ingatan tentang karakter kebaikan serta dampak yang ditimbulkannya. Ini ditemukan terinspirasi dari surat dan ayat Alquran yang memiliki kandungan term "khair" yang berarti "baik" antara lain terdapat dalam Alquran surat Al-Qadr [97]:1-5.
4. Untuk proses pembelajaran agar mampu melakukan proses membangkitkan penguatan "motivasi" terhadap proses pemodelan "produk" yang dibangun untuk membantu proses mengeluarkan "retensi" ingatan tentang karakter kebaikan dan keburukan serta dampak yang ditimbulkannya. Ini ditemukan terinspirasi dari surat dan ayat Alquran yang memiliki kandungan term "muhsin" yang berarti "berakhlak baik" antara lain terdapat dalam Alquran surat Al-Mursalât [77]:41-45.

Metode Tafsir Al-Maudlu'i dimplementasikan untuk mengkaji setiap surat dan ayat Alquran yang terkait dalam penelitian ini. Untuk term-term pendukung dicari dalam Alquran dengan menggunakan bantuan Zekr (Software Komputer, Proyek Qur'an Dzikir, Versi 1.10. zekr.org). Adapun model implementasi dari konsep pendidikan karakter indigenous dalam perspektif Alquran dikaji berdasarkan gabungan beberapa teori di antaranya dari Syafri (2012: 99-148) serta Abdul Majid dan Dian Andayani yang dinamakan TADZKIROH- (Majid \& Andayani, 2013: 116-117), sehingga kolaborasi dari kedua pemikiran dimaksud, disebut dengan TADZKIROH PLUS.

\section{PENUTUP}

Dari pembahasan yang sudah diungkapkan di atas dapat dikemukakan beberapa simpulan sebagai berikut. 1) Manusia dalam 
perspektif sains dan Alquran memiliki dua jenis karakter indigenous yang berpasangan dan bersifat saling berlawanan, yakni karakter kebaikan (taqwa) dan karakter keburukan (fujur); 2) Ada relasi antara pendidikan karakter indigenous dengan berbagai sains: ilmu naqliyah, ilmu 'aqliyyah, dan ilmu 'amaliyyah; 3) Ada beberapa nilai karakter indigenous yang pokok, seperti religius, cinta tanah air, dan intelektualitas yang bernuansa kebaikan (taqwā), dan bernuansa keburukan (fujür); dan 4) Ditemukannya rumusan konsep pendidikan karakter indigenous dalam perspektif Alquran yang disebut model implementasi "TADZKIROH PLUS" serta implementasinya untuk masa pranikah, prenatal, dan golden age.

Hasil penelitian ini diharapkan dapat memberikan sumbangan pemikiran terhadap pelaksanaan pendidikan karakter di Indonesia, juga ikut serta memberikan solusi pemecahan masalah terhadap semakin berkembang dan meluasnya dekadensi karakter di Indonesia pada saat ini. Akhirnya perlu ditegaskan bahwa pendidikan karakter indigenous dalam perspektif Alquran berupaya mengoptimalisasi karakter kebaikan manusia dan meminimalkan karakter keburukan manusia sehingga dapat mengatasi terjadinya berbagai dekadensi moral di tengah masyarakat Indonesia yang sangat kompleks.

\section{UCAPAN TERIMA KASIH}

Dengan terselesaikannya penelitian dan artikel ini, penulis mengucapkan terima kasih kepada semua pihak yang telah membantu kelancaran penelitian hingga penulisan artikel ini. Secara khusus penulis mengucapkan terima kasih kepada Prof. Dr. H. Nasaruddin Umar, M.A. dan Dr. Hj. Nur Arfiyah Febriani, M.A. selaku pembimbing disertasi atas segala kebaikan, kesantunan, dan kesabarannya dalam menemani penulis hingga penulis dapat menyelesaikan studi S3.

\section{DAFTAR PUSTAKA}

Al-Qattan, M. K. (2015). Studi ilmu-ilmu Qur'an. Diterjemahkan oleh Mudzakir AS. Jakarta: Litea Antar Nusa.

Al-Qur'an al-Karim.

Badan Pusat Statistik. (2017). Statistik kriminal 2017. Retrieved from https://www.bps.go.id/ publication/2017/12/22/1975 62b7ad0ced87c08fada5/statist ik-kriminal-2017.html.

Bloom, B. S., Engelhart (1959). The taxonomy of educational objectives the classification of educational goals. Handbook 1: Cognitive Domain. New York: David McKay.

Dettmer, P. (2006). New Blooms in established fields: Four domains of learning and doing. Roeper Review, 28(2), 70-78. DOI: $\underline{10.1080 / 02783190609554341 .}$. 
Hasan, S. H. (2010). Pengembangan pendidikan budaya karakter bangsa. Jakarta: Kementerian Pendidikan Nasional.

Kim, U., Yang, K., \& Hwang, K. (2006). Contributions to indigenous and cultural psychology: Understanding people in context. International and Cultural Psychology Series. New York: Springer. DOI: $\quad$ 10.1007/0-387-286624_1.

Komnas Perempuan. (2016). Pemerkosaan berjamaah: Indonesia darurat kekerasan seksual? Retrieved from https://www.dw.com/id/pemer kosaan-berjamaah-indonesiadarurat-kekerasan-seksual/a19233807.

Krisnawan. (2010). Peran dan kesejahteraan pendidik sebagai cerminan kemajuan pendidikan di Indonesia. Retrieved from https://docplayer.info/5200302 9-Menurut-survei-politicaland-economic-risk-consultantperc-kualitas-pendidikan-diindonesia-berada-pada-urutanke-12-dari-12-negara-diasia.html.

Kumpulan hadis-hadiss al-Kutub alTis'ah (9 Imam: al-Bukhari, Muslim, Abu Daud, alTirmidzi, al-Nasa'i, Ibnu Majah, Ahmad, Malik, dan alDarimi) Lidwa Pustaka iSoftware - Kitab 9 Imam Hadis, CD-Room.
Lajnah Pentashihan Mushaf Alquran (LPMA). (2010). Alquran tafsir tematik: Pendidikan, pembangunan karakter, dan pengembangan sumber daya manusia - Seri 4. Jakarta: Badan Litbang dan Diklat Kementrian Agama RI.

Lickona, T. (1991). Educating for character: How our schools can teach respect and responsibility. New York, Toronto, London, Sydney, Aucland: Bantam books.

Liputan 6. (Mei 2015). Mengapa Indonesia darurat narkoba? Retrieved from http://news.liputan6.com/read/ 2233219/mengapa-indonesiadarurat-narkoba.

Majid, A. \& Andayani, D. (2013). Pendidikan karakter perspektif Islam. Bandung: Remaja Rosdakarya.

Peraturan Menteri Pendidikan dan Kebudayaan Republik Indonesia Nomor 84 Tahun 2014 Tentang Pendidikan Anak Usia Dini.

Peraturan Presiden Nomor 87 Tahun 2017 tentang Penguatan Pendidikan Karakter

Reza, S. (2014). Konsep nafs menurut Ibnu Sina. Kalimah: Jurnal Studi Agama dan Pemikiran Islam, 12(2), 263279.

DOI:

10.21111/klm.v12i2.239.

Rosidin. (2015). Metodologi tafsir tarbawi. Jakarta: Amzah. 
Samani, M. \& Hariyanto. (2012). Konsep dan model pendidikan karakter. Bandung: Remaja Rosdakarya.

Santrock, J. W. (2014). Educational psychology: Psikologi pendidikan, Edisi 5, Buku 1., Terjemah oleh Harya Bimasena. Jakarta: Salemba Empat.

Shihab, M. Q. (2005). Tafsir alMishbah: Pesan kesan dan keserasian Alquran. Jakarta: Lentera Hati.

Syafri, U. A. (2012). Pendidikan karakter berbasis al-Qur'an. Jakarta: PT. Raja Grafindo Persada.

Taufiq, M. (2018). DPR dan MUI sepakat LGBT dipidana dalam RKUHP. Retrieved from

https://nasional.tempo.co/read/ 1057953/dpr-dan-mui-sepakatlgbt-dipidana-dalamrkuhp/full\&view=ok.

The Economist Intelligence Unit. (2012). The Learning curve: Lesson in country performance in education: 2012 report. London: Pearson Plc.
The Economist Intelligence Unit. (2014). The learning curve: Lesson in country performance in education: 2014 report. London: Pearson Plc.

Undang-Undang Nomor 20 Tahun 2003 tentang Sistem Pendidikan Nasional.

Undang-Undang Nomor 35 Tahun 2014 tentang Perubahan atas Undang-Undang Nomor 23 Tahun 2002 tentang Perlindungan Anak.

UNESCO. (2011). The hidden crisis, armed conflict and education. EFA Global Education Monitoring Report 2011. Retrieved from https://en.unesco.org/gemreport/report/2011/hiddencrisis-armed-conflict-andeducation.

Wapres RI. (Desember, 2014). Kebijakan bukan bagian perkara. Retrieved from http://www.wapresri.go.id/kebijakanbukan-bagian-perkara. 